\title{
Normal Hearing Function in Children Prenatally Exposed to Zika Virus
}

\author{
Maria Helena Magalhães Barbosa,20 Cristiane Fregonesi Dutra Garcia ${ }^{3}$ \\ Maria Clara de Magalhães Barbosa ${ }^{2}$ Jaqueline Rodrigues Robaina ${ }^{4}$ Arnaldo Prata-Barbosa ${ }^{2,5}$ \\ Marco Antonio de Melo Tavares de Lima ${ }^{1}$ Antonio José Ledo Alves da Cunha ${ }^{5,6}$
}

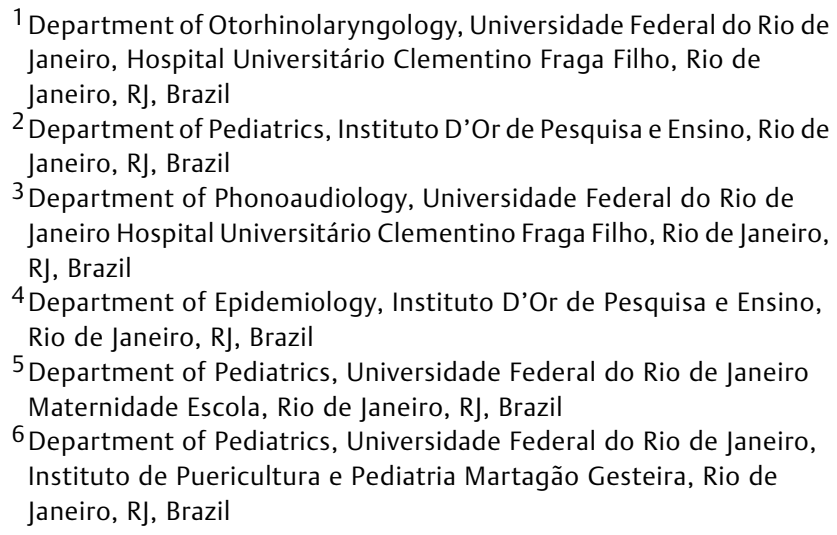

Address for correspondence Maria Helena de Magalhães Barbosa, Master, Department of Otorhinolaryngology, Universidade Federal do Rio de Janeiro Hospital Universitário Clementino Fraga Filho, Rua Prof Rodolpho Paulo Rocco, 255 Ilha do Governador, Rio de Janeiro, RJ, 21941-913, Brazil (e-mail: mariahelena_barbosa@yahoo.com.br).

Int Arch Otorhinolaryngol 2020;24(3):e299-e307.

\begin{abstract}
Introduction The association between prenatal Zika virus infection and hearing alterations in offspring has been the object of some studies, although few have assessed children without microcephaly. However, a current trend to include prenatal Zika virus exposure in the group of risk indicators for hearing loss is noted.

Objective To present a series of 27 children prenatally exposed to the Zika virus submitted to multiple hearing assessments over time.

Methods A cohort of children born to symptomatic mothers with laboratorial Zika virus infection confirmation during pregnancy was submitted to an otoacoustic emission test, auditory brainstem response test (automated, neurodiagnostic and frequency-specific), audiometry, and imitanciometry over a period of 36 months since birth. The hearing assessment was performed independently of the presence of microcephaly or other apparent signs of congenital Zika syndrome.

Results The hearing tests presented predominantly normal results. Some children had signs of middle ear pathology. The only microcephalic child had normal electrophysiological tests, as well as preserved audiometric thresholds, but presented altered motor responses to sound.

Keywords

- zika virus

- hearing

- prenatal injuries

Conclusion Prenatal exposure to Zika virus does not always determine hearing impairment. This risk seems to be more associated to the severity of the central nervous system damage. Hearing screening and follow-ups of the affected children are important, as well as further research in this area.
\end{abstract}

received

April 16, 2019

accepted

September 27, 2019

published online

December 13, 2019
DOI https://doi.org/

10.1055/s-0039-3399539.

ISSN $1809-9777$.
Copyright $\odot 2020$ by Thieme Revinter

Publicações Ltda, Rio de Janeiro, Brazil
License terms

(c) (i) $\ominus$ (\$) 


\section{Introduction}

The relationship between congenital Zika virus (ZIKV) infection and hearing impairment has been studied, especially after the Latin American epidemic in 2015, with reports of sensorineural hearing loss in affected children with microcephaly. ${ }^{1,2}$ The occurrence of neurological and ocular alterations and multiple malformations has raised the hypothesis of a possible association of Zika infection with hearing impairments, as demonstrated in other congenital infections. ${ }^{3-5}$ However, few studies to date have assessed the hearing function of infected children without microcephaly. ${ }^{6,7}$ On the other hand, ocular findings in non-microcephalic children have been reported. ${ }^{8}$

The hearing screening of children with risk indicators for hearing loss must be conducted by the otoacoustic emission (OAE) and the auditory brainstem response (ABR) tests. ${ }^{9}$ Congenital infections such as syphilis, cytomegalovirus, toxoplasmosis, and rubella are hearing loss indicators. ${ }^{10}$ Based on existing reports, a trend to include children with congenital ZIKV infection in this group is noted. ${ }^{2,11-14}$ Furthermore, it is recommended that children in the risk group are followed-up by developmental milestone surveillance, hearing abilities, and middle ear conditions. At least one audiological evaluation should be performed between 24 and 30 months of age, due to the risk of progressive or late onset hearing loss. ${ }^{9}$

Although the incidence of new cases is currently declining, the risk of a new epidemic is constant, as the mosquito vector and favorable climatic conditions for its proliferation are present in many countries, in addition to increasing global mobility of people. Moreover, many infected individuals, notably children affected by congenital Zika syndrome (CZS), exhibit outcomes due to the infection and, therefore, require regular multidisciplinary follow-up. Further studies on the consequences of this infection in the human body are necessary to support screening, management and follow-up recommendations of individuals exposed to the ZIKV.

\section{Objective}

The aim of the present study is to present the results of the hearing assessments of 27 children born to mothers with laboratorial confirmation of ZIKV infection during pregnancy.

\section{Methods}

This is an observational, descriptive and longitudinal study of a cohort of 27 children followed from birth to $\sim 36$ months. The study was conducted in a public university maternity hospital, where $50 \%$ of the patients are high-risk pregnant women referred to the institution and the remaining are normal pregnancies from the surrounding neighborhood. Most of the mother and child study procedures were performed in the maternity hospital, such as information collection, blood sample collection for laboratorial tests, otoacoustic emission (OAE) hearing tests, neurodiagnostic auditory brainstem response (ABR) and frequency-specific ABR (FS-ABR). The automated $A B R(a-A B R)$, imitanciometry and audiometry tests were performed in a quaternary public hospital belonging to the same university. Efforts to reduce missing tests in the follow-up phase were made, such as more than one telephone contact, transport reimbursement and more than one option of days to attend the reevaluation visits.

All infants born to mothers admitted to the maternity hospital from December $1^{\text {st }} 2015$ to June $30^{\text {th }} 2017$ with laboratorial confirmation of ZIKV infection during pregnancy were included. Exclusion criteria comprised refusal to sign the free and clarified consent term (FCCT) and the presence of infant malformations that precluded the performance of the auditory tests. Participants that withdrew consent after the start of the study and those that could not, for any reason, be submitted to the hearing tests were classified as losses.

Pregnant women presenting a clinical disease consistent with ZIKV infection gave a blood sample collected up to the $5^{\text {th }}$ day of symptoms and a urine sample collected up to the $28^{\text {th }}$ day from symptom onset to perform a reverse transcriptase polymerase chain reaction (RT-PCR) test. In addition, a blood sample was collected between the $7^{\text {th }}$ and the $14^{\text {th }}$ day for immunoglobulin $\mathrm{M}(\mathrm{IgM})$ and immunoglobulin $\mathrm{G}(\mathrm{IgG})$ tests. An umbilical cord blood sample was also collected for an IgM test to eventually confirm newborn infection. Simultaneously, serologies for dengue virus (DENV), chikungunya virus (CHIKV), and for the syphilis, toxoplasmosis, rubella, cytomegalovirus and herpes (STORCH) group were collected to discard infection by these agents. Some mothers with suspected or confirmed ZIKV infection gave urine samples throughout their gestation for ZIKV RT-PCR testing. Laboratorial evidence of maternal infection by ZIKV was considered as: 1) detection of ZIKV RNA by RT-PCR in blood and/or urine; 2) positive IgM serology for ZIKV, and negative IgM serology for DENV.

Pregnant women with laboratorial evidence of ZIKV infection were considered as confirmed cases. Therefore, their newborns were eligible for the study. Suspected cases of ZIKV infection with no laboratorial confirmation were not eligible.

The children included in the study were scheduled for hearing function exams comprising OAE, a-ABR, FS-ABR, neurodiagnostic $A B R$, imitanciometry (tympanometry + acoustic reflex test) and audiometry assessments. Regarding neonatal hearing screening, OEA exhibited sensitivity of 0.77 (confidence interval $[\mathrm{Cl}] 95 \% 0.65-0.86)$ and specificity of $0.93(\mathrm{Cl}$ 95\% 0.92-0.93), and a-ABR exhibited sensitivity of 0.93 (CI 95\% 0.87-0.96) and specificity of 0.97 (CI 95\% 0.96-0.98), compared with ABR. ${ }^{15}$ Audiometry is the gold standard for hearing loss diagnoses, but FS-ABR is considered an accurate test to estimate hearing thresholds in infants that cannot cooperate with audiometry. ${ }^{16,17}$ Neurodiagnostic ABR is used to verify the conductibility of the auditory pathways. There is evidence that the combination of these tests (imitanciometry + OAE) improves sensitivity without compromising specificity (sensitivity of 0.86 and specificity of 0.96$).{ }^{18}$

Right before each exam, the acoustic meatus and tympanic membranes of the infants were inspected with an otoscope. Most children performed the OEA test within $24 \mathrm{~h}$ to $48 \mathrm{~h}$ of life, and, in some cases, up to 25 days from birth. The hearing assessment by the OAE and ABR tests were performed according to the Care Guidelines for Newborn 
Hearing Screening from the Brazilian Ministry of Health ${ }^{19}$ and following the BC Children's Hospital practice guidance procedures. $^{20}$ The Otoport Lite OEA DP + TE (Otodynamics, Hatfield, Hertfordshire, England) device, ${ }^{21}$ with a non-linear click stimulus comprising frequencies from $1 \mathrm{kHz}$ to $5 \mathrm{kHz}$ and equivalent peak of intensity around $84 \mathrm{dBHL}$, was used. A stimulus stability of $70 \%$ or higher was considered adequate for exam validity. The standard noise rejection value was 47 dBHL. For the test to be considered positive (indicating a present OEA), the signal-to-noise ratio (SNR) should be at 3 to $6 \mathrm{~dB}$, and the reproducibility for each frequency band or general of over $50 \%$. The a-ABR was performed in a silent sound isolated room, with the child under natural sleep, using the Intelligent Hearing Systems - IHS4754 (Intelligent Hearing Systems, Miami, FL, USA). ${ }^{22}$ A maximum individual impedance of $5 \mathrm{k} \Omega$ was admitted between the electrodes and the skin, and intraelectrode impedances were less than $3 \mathrm{k} \Omega$. The test was performed using insert earphones, elicited by $100 \mu$ s rarefaction clicks, presented at a rate of $15.1 / \mathrm{s}$ and stimulus level of $80 \mathrm{dBHL}$, and with progressive decrease to establish a minimal auditory response level, which is the intensity of the stimulus at which the wave $\mathrm{V}$ could be identified and replicated. Responses from 2,000 to 4,000 stimulus presentations were averaged. The filters were set from 100 to 3,000 Hz, and a recording window of $15 \mathrm{~ms}$ was used. The neurodiagnostic ABR and the FS-ABR were performed using the Eclipse EP15 (Interacoustics) device ${ }^{23}$ with insert earphones. The impedance criteria and filters were the same used for the a-ABR. The recording window was of $20 \mathrm{~ms}$. For the neurodiagnostic ABR, a click stimuli presentation of $100 \mu \mathrm{s}$ at $80 \mathrm{dBHL}$ at alternating polarities was set up, with a sound presentation rate of $21.1 / \mathrm{s}$, for the auditory pathways integrity verification. The presence or absence of waves and their morphology and reproducibility were assessed, and the study of cochlear microphonic potentials was performed when necessary. The FS-ABR was performed with tone-burst stimuli at $0.5 \mathrm{kHz}, 1 \mathrm{kHz}, 2 \mathrm{kHz}$ and $4 \mathrm{kHz}$ to establish the minimal auditory response level for each frequency, using alternating polarities and a sound presentation rate of $39.1 / \mathrm{s}$. At least 2,000 stimuli were presented to register the response. Responses $\leq 35 \mathrm{dBnHL}$ for $0.5 \mathrm{kHz}$ and $\leq 30 \mathrm{dBnHL}$ for $1 \mathrm{kHz}, 2 \mathrm{kHz}$, and $4 \mathrm{kHz}$ were considered normal. ${ }^{17,20}$ As the children were already 1 to 2 years of age by the time they performed this test, they sedated, by the oral administration of $20 \%$ chloral hydrate performed by a trained pediatrician, acquainted with this procedure. The imitanciometry test was performed after 2 years of age, right before the audiometry assessment and after ear, nose, mouth and throat examinations. A tympanogram and the stapedial reflex test were performed using a Kamplex AZ7-R imitanciometer (Interacoustics). ${ }^{23}$ Depending on the age and cooperation level of each child, a vocal and pure tone audiometry was performed with conditioned play and/or visual reinforcement, in an open field (to establish the minimal level of response) or with headsets (to establish the hearing threshold in each ear). Alternatively, a behavioral audiometry was performed. Responses $\leq 20 \mathrm{~dB}$ were considered as normal.
The sample size was determined by convenience, corresponding to the number of participants included while the study admitted new participants.

The study was submitted to the research ethics committee of the proponent institute and was approved under protocol number 1.516.904.

\section{Results}

Of the 31 eligible pregnant women and their 32 children (one twin case), 2 newborns were excluded because the parents refused to sign the FCCT. Three losses comprising discontinued follow-up were noted.

All included pregnant women presented laboratorial confirmation of ZIKV infection, 24 (92.3\%) by means of a positive RT-PCR and 2 (7.7\%) exclusively by positive IgM serology. Nine (34.6\%) had the infection in the $1^{\text {st }}$ trimester, 10 (38\%) in the $2^{\text {nd }}$ trimester, and 7 (26.9\%) in the $3^{\text {rd }}$ trimester.

Only one infant exposed to the virus during the first trimester presented microcephaly. No children tested positive for umbilical cord blood IgM serology, including the infant with microcephaly. We ruled out STORCH group infection in the mothers. The main clinical and sociodemographic characteristics of the mothers and children are displayed in the - Table 1.

Only three children were submitted to all hearing tests, mainly due to family difficulties in bringing their children to the visits. Seventeen children (63\%) had OAE + any type of $\mathrm{ABR}+$ audiometry + imitanciometry testing and 20 (74\%) were submitted to FS-ABR or audiometry + imitanciometry (-Table 2).

Most children presented normal hearing tests. Seven (38.9\%) presented a hearing evaluation suggestive of middle ear alterations in at least one of the ears at the time of the audiometric/imitanciometric test. All of those children (7) presented congested upper airways at the time of the exam (i.e., congested mucosa, rhinorrhea, report of recent upper airway infection or allergic exacerbation). One of the children (n.2) had already presented this type of condition since the neurodiagnostic ABR test, at 23 months of life, in which delayed wave absolute latencies were identified. This child was referred to otolaryngologic evaluation and follow-up and was diagnosed with bilateral chronic otitis media with effusion (-Table 3 ).

The only microcephalic child in the cohort presented normal electrophysiological tests, with normal electrophysiological hearing thresholds for both ears. Her imitanciometry test was normal, presenting a bilateral "A" type curve in the tympanogram and present ipsilateral and contralateral stapedial reflex in every tested frequency. The blink reflex was present during the behavioral audiometry, and the patient reacted to every instrument at all intensities. However, her motor reactions were always directed to the left side, even for stimuli presented on the right side.

\section{Discussion}

This study demonstrates that a sample of children presenting prenatal exposure to ZIKV assisted in a public health service, 
Table 1 Clinical and sociodemographic characteristics of the mothers and children assessed in the present study

\begin{tabular}{|c|c|}
\hline \multicolumn{2}{|l|}{ Clinical characteristics } \\
\hline \multicolumn{2}{|l|}{ Mothers $(n=26)$} \\
\hline Age at child birth & $\begin{array}{l}\text { median (IQR) } \\
29(23.5-33.5)\end{array}$ \\
\hline Trimester when the infection occurred & $\mathrm{n}(\%)$ \\
\hline $1^{\text {st }}$ trimester & $9(34.6)$ \\
\hline $2^{\text {nd }}$ trimester & $10(38.5)$ \\
\hline $3^{\text {rd }}$ trimester & $7(26.9)$ \\
\hline Schooling level & $\mathrm{n}(\%)$ \\
\hline Elementary school & $6(23.1)$ \\
\hline Middle/High school & $15(57.7)$ \\
\hline Higher education & $4(15.4)$ \\
\hline Not known & $1(3.8)$ \\
\hline $\begin{array}{l}\text { Comorbidity related to gestation } \\
\text { (ex. PIH, gestational DM, etc) }\end{array}$ & $10(38.5)$ \\
\hline Pre-existing chronic diseases & $9(34 / 6)$ \\
\hline $\begin{array}{l}\text { STD diagnostic/treatment } \\
\text { before the pregnancy }\end{array}$ & $3(11.5)$ \\
\hline \multicolumn{2}{|l|}{ Children $(n=27)$} \\
\hline Gestational age at birth & $\mathrm{n}(\%)$ \\
\hline$<28$ weeks & $0(0.00)$ \\
\hline 28-32 weeks & $3(11.1)$ \\
\hline 33-36 weeks & $1(3.7)$ \\
\hline 37-41 weeks & $23(85.2)$ \\
\hline$\geq 42$ weeks & $0(0.00)$ \\
\hline Sex & $\mathrm{n}(\%)$ \\
\hline Female & $20(74.1)$ \\
\hline Male & $7(25.9)$ \\
\hline Microcephaly & $1(3.7)$ \\
\hline Other congenital malformations & $0(0.00)$ \\
\hline NICU admission & $3(11.1)$ \\
\hline Use of ototoxic medications & $0(00.0)$ \\
\hline Hyperbilirubinemia & $4(14.8)$ \\
\hline Familiar history of hearing loss & $5(18.5)^{a}$ \\
\hline
\end{tabular}

Abbreviations: DM, diabetes mellitus; IQR, interquartile range; NICU, neonatal intensive care unit; $\mathrm{PIH}$, pregnancy-induced hypertension, STD, sexually transmitted disease.

a one presenting congenital hearing loss (sister), one presenting presbyacusis (grandfather), one presenting hearing loss after cranioencephalic trauma (father), one presenting possible noise-induced hearing loss (father) and one with progressive hearing loss of unknown cause (great-aunt).

most of which with no apparent abnormalities suggestive of CZS, displayed predominantly normal hearing evaluations. According to the World Health Organization's (WHO) interim guidance update (2016), ${ }^{24}$ all included pregnant women presented laboratorial confirmation of ZIKV infection. However, only the infant with microcephaly could be considered
Table 2 Child distribution for each hearing test

\begin{tabular}{|l|l|}
\hline \multicolumn{2}{|l|}{ Hearing tests } \\
\hline Type of test & $\mathbf{n}(\%)$ of children submitted \\
\hline T-OAE & $27(100)$ \\
\hline a-ABR & $14(52)^{\mathrm{a}}$ \\
\hline Neuro-ABR & $11(41)$ \\
\hline FS-ABR & $10(37)$ \\
\hline Audiometry & $18(67)$ \\
\hline Imitanciometry & $18(67)$ \\
\hline
\end{tabular}

Abbreviations: a-ABR, automated auditory brainstem responses; FS$A B R$, frequency specific auditory brainstem responses; neuro- $A B R$, neurodiagnostic (click) auditory brainstem responses; T-OAE, transient otoacoustic emissions.

${ }^{a}$ of the total, three presented unreliable testing results in one of the ears.

a case definition of brain abnormality with an epidemiological link to ZIKV, as the guidance does not define cases without apparent neurologic abnormalities.

Although prenatal exposure to the ZIKV occurred predominantly in the first two trimesters in this cohort, when a greater risk of impairment of fetal development is noted, ${ }^{25}$ most children did not present apparent CZS signs, which can explain the lack of hearing impairment. Most studies identifying hearing loss in ZIKV infection were conducted with microcephalic children, ${ }^{2,26-28}$ which suggests that hearing impairment manifestations are related to a worse spectrum of clinical involvement or even association to central alterations.

Considering the accuracy of the combined tests, normal hearing evaluation results were observed in the present study, both related to neural auditory pathway conduction and hearing threshold, indicate that the assessed children's hearing function was not affected by prenatal exposure to the ZIKV, neither at birth or after. Some of the children showed results suggesting middle ear pathology, but associated to a recent history of upper airway infection, chronic nasal obstruction and/or otitis media with effusion. These results are consistent with other reports. ${ }^{13,14,28,29}$

Leite et $\mathrm{al}^{29}$ performed hearing tests in 45 children born to mothers with evidence of ZIKV infection not necessarily presenting microcephaly. The authors also report a few cases suggesting middle ear pathology, but no evidence of sensorineural hearing loss, and stated that middle ear effusion is a remarkable finding in young children. However, they performed a cross-sectional study only by a screening approach applying imitanciometry, OAE, and blink reflex testing.

Fandiño-Cárdenas et $\mathrm{al}^{14}$ performed hearing tests in children prenatally exposed to the ZIKV, including children with and without microcephaly. The evaluation included OAE, tympanometry, and ABR assessments at 3 and 24 months of age, with no significant alterations found in any of the situations. However, the authors indicate that, given the possibility of a progressive hearing loss in ZIKV congenital infection, an auditory follow-up is recommended during the first 5 years of life. 


\begin{tabular}{|c|c|c|c|c|c|c|c|c|c|}
\hline 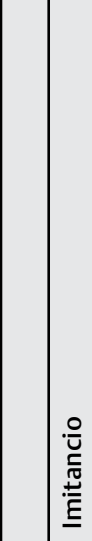 & 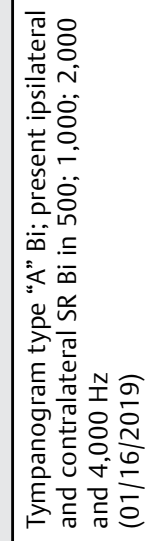 & 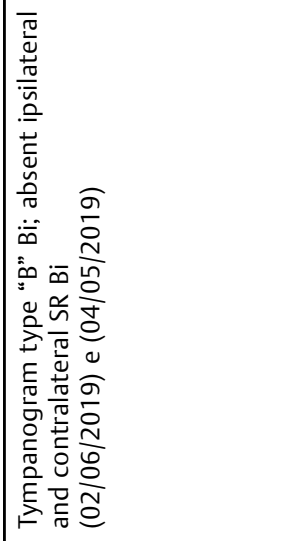 & 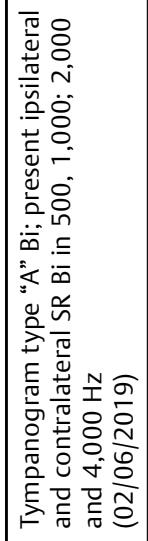 & $\frac{1}{2}$ & 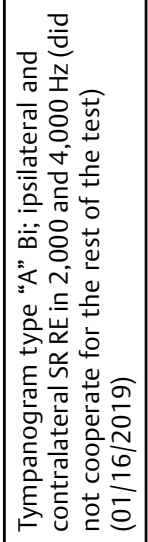 & 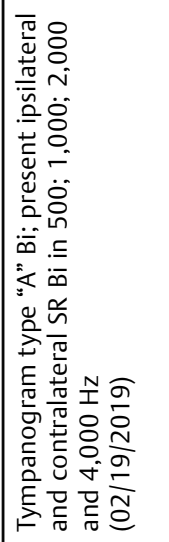 & 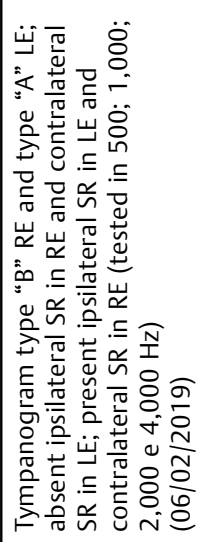 & $\frac{1}{2}$ & 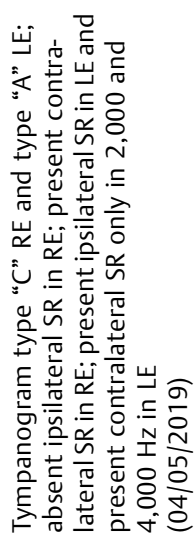 \\
\hline$\frac{\circ}{\bar{y}}$ & 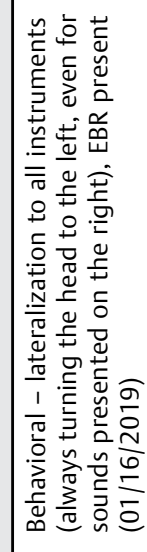 & 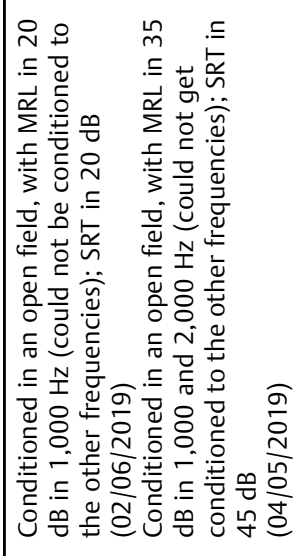 & 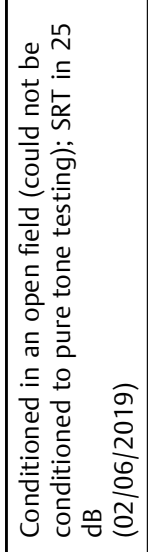 & $\frac{1}{z}$ & 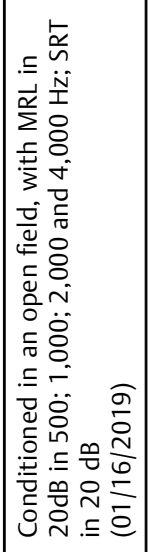 & 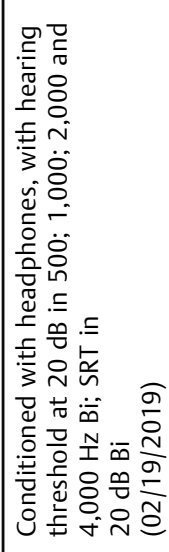 & 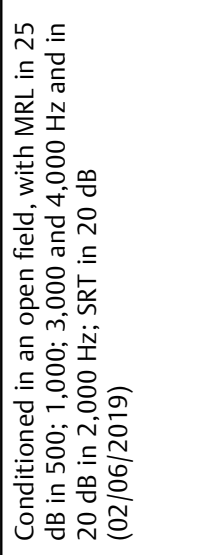 & $\frac{\rho}{z}$ & 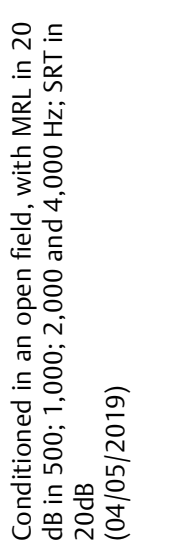 \\
\hline 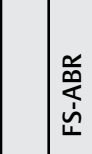 & 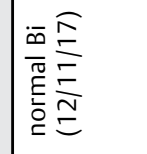 & $\frac{n}{z}$ & 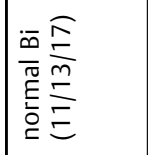 & 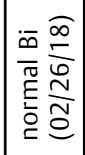 & 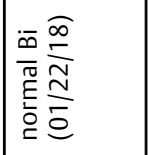 & 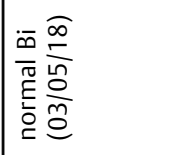 & 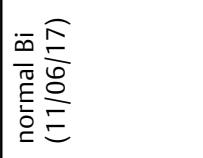 & 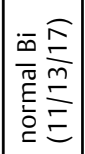 & 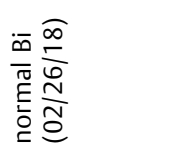 \\
\hline 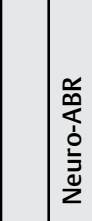 & : & 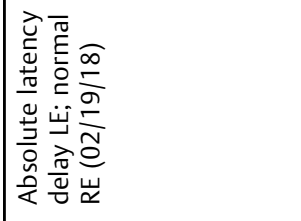 & 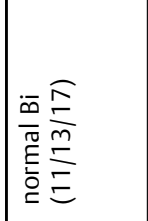 & 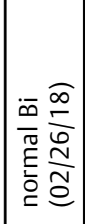 & 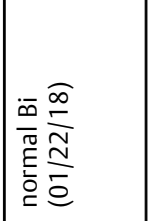 & 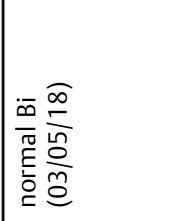 & 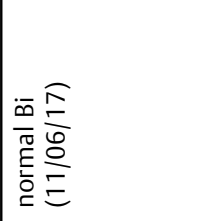 & 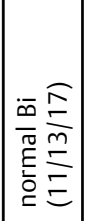 & 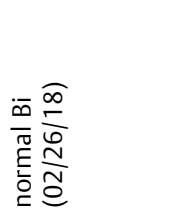 \\
\hline 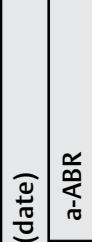 & 勿 & $\frac{\varrho}{z}$ & $\frac{\alpha}{z}$ & z & $\bar{z}$ & 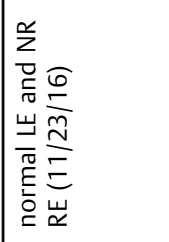 & 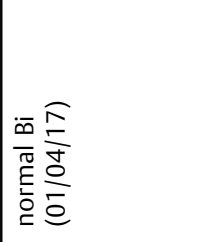 & $\frac{\hat{z}}{z}$ & $\bar{z}$ \\
\hline 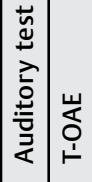 & 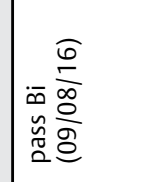 & 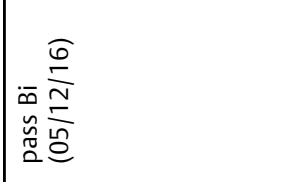 & 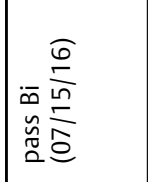 & 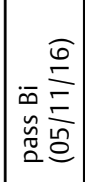 & 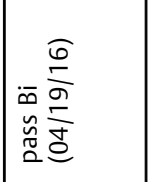 & 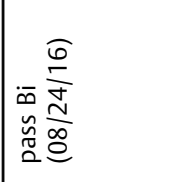 & 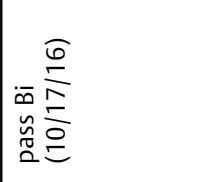 & 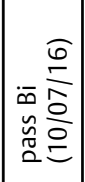 & 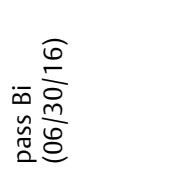 \\
\hline 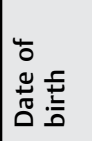 & $\frac{\frac{0}{0}}{\frac{0}{8}}$ & $\frac{\frac{0}{2}}{\frac{\partial}{2}}$ & 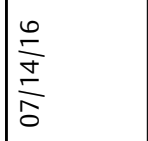 & $\frac{0}{\frac{0}{n}}$ & $\frac{\frac{0}{2}}{\frac{\frac{1}{9}}{\delta}}$ & $\frac{0}{\frac{0}{\frac{1}{6}}}$ & 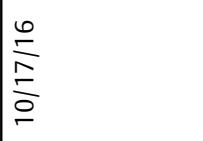 & $\begin{array}{l}\frac{0}{2} \\
\frac{\hat{\alpha}}{0} \\
\frac{0}{0}\end{array}$ & $\begin{array}{l}\frac{6}{2} \\
\frac{2}{\frac{N}{8}}\end{array}$ \\
\hline 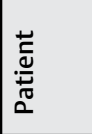 & - & $\sim$ & $m$ & $\sigma$ & in & 6 & $\wedge$ & $\infty$ & $a$ \\
\hline
\end{tabular}




\begin{tabular}{|c|c|c|c|c|c|c|c|c|c|c|}
\hline 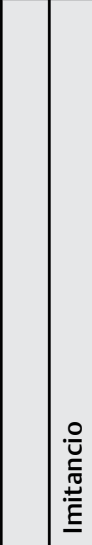 & 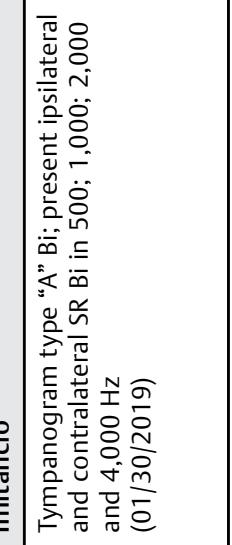 & 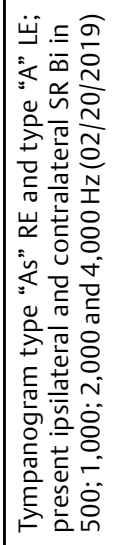 & 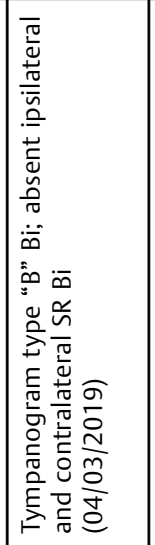 & 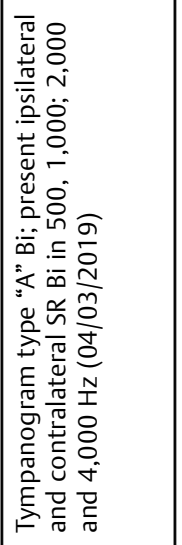 & $\frac{n}{z}$ & 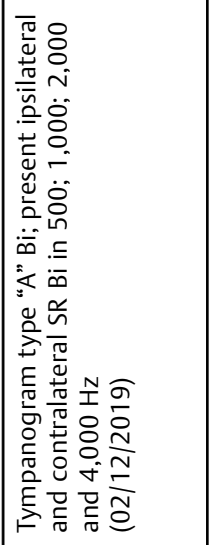 & 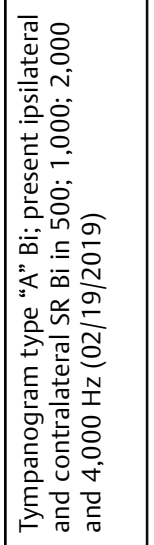 & 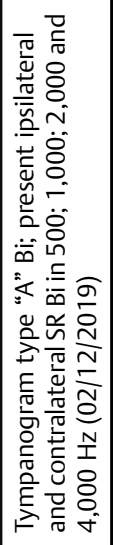 & 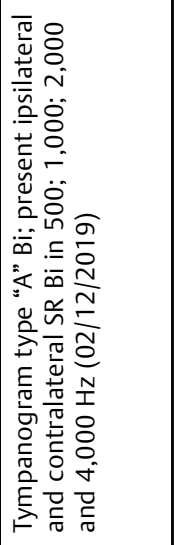 & $\frac{\hat{z}}{2}$ \\
\hline$\frac{\circ}{\bar{y}}$ & 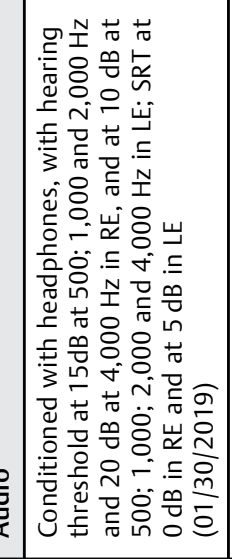 & 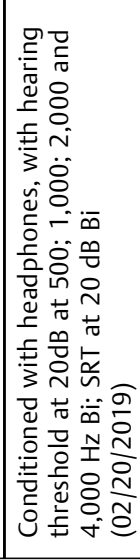 & 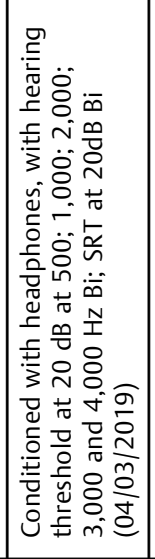 & 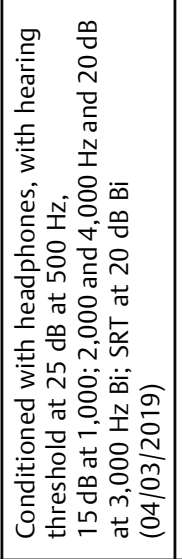 & $\frac{1}{2}$ & 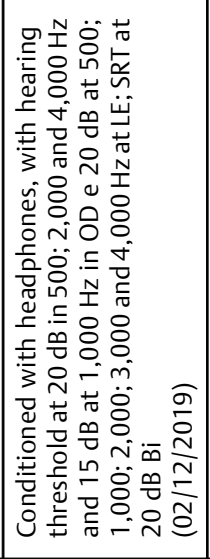 & 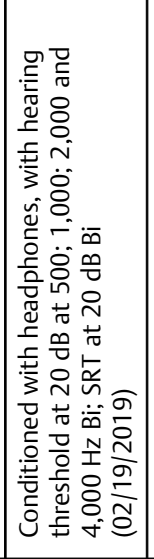 & 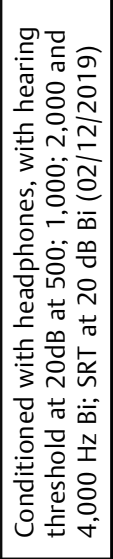 & 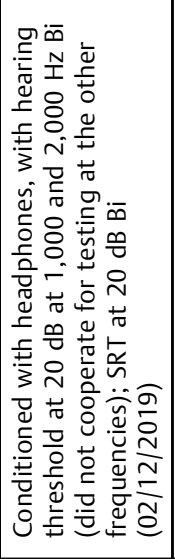 & $\bar{z}$ \\
\hline 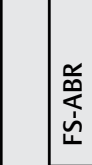 & 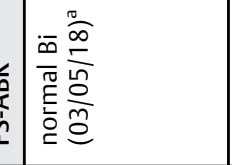 & 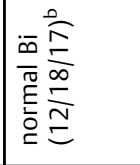 & $\frac{\hat{z}}{z}$ & $\frac{\hat{z}}{2}$ & $\frac{n}{z}$ & $\frac{n}{z}$ & $\frac{\hat{z}}{2}$ & $\frac{n}{z}$ & $\frac{\hat{z}}{2}$ & $\bar{z}$ \\
\hline 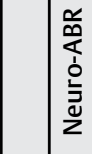 & 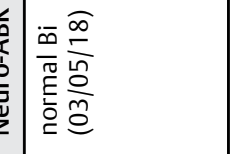 & 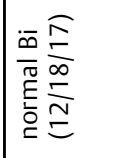 & $\frac{o}{z}$ & $\frac{\hat{z}}{2}$ & $\frac{n}{z}$ & $\frac{1}{z}$ & $\frac{n}{z}$ & $\frac{n}{z}$ & $\frac{\varrho}{z}$ & $\frac{\varrho}{z}$ \\
\hline 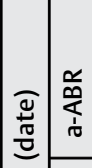 & 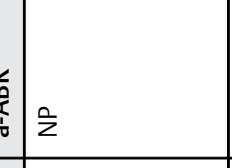 & $\hat{z}$ & 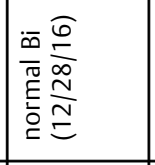 & 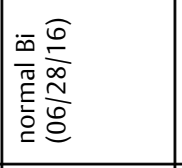 & 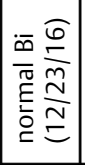 & 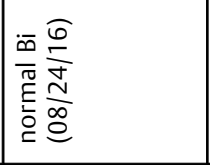 & 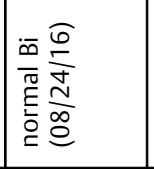 & 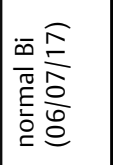 & 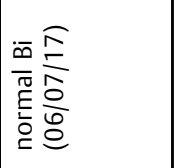 & $\hat{z}$ \\
\hline 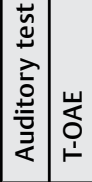 & 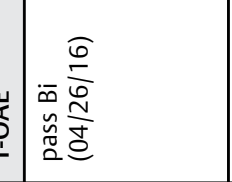 & 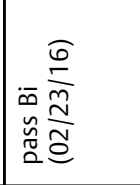 & 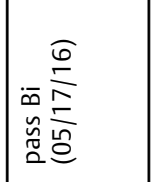 & 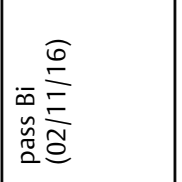 & 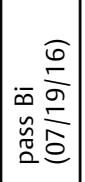 & 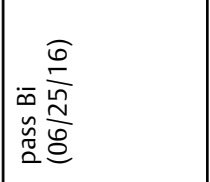 & 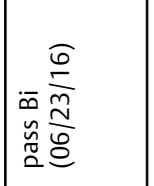 & 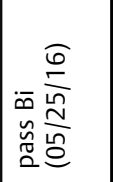 & 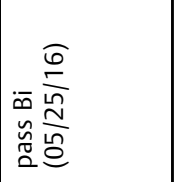 & 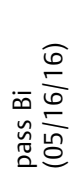 \\
\hline 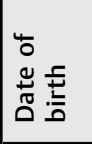 & $\mid$ & $\frac{\stackrel{0}{\tilde{N}}}{\frac{\underline{N}}{\tilde{\sigma}}}$ & $\frac{0}{\frac{0}{6}}$ & $\frac{0}{\frac{0}{3}}$ & $\underset{\frac{0}{}}{\stackrel{ }{\frac{1}{\delta}}}$ & $\frac{\frac{0}{3}}{\frac{\hat{\alpha}}{8}}$ & $\frac{0}{\frac{0}{n}}$ & $\frac{0}{\frac{0}{b}}$ & $\frac{0}{\frac{0}{0}}$ & 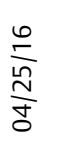 \\
\hline 苞 & $\stackrel{\circ}{\circ}$ & $=$ & $\simeq$ & $m$ & $\stackrel{\nabla}{\square}$ & $\stackrel{n}{\square}$ & $\stackrel{\varphi}{\circ}$ & 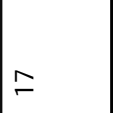 & $\stackrel{\infty}{-}$ & 9 \\
\hline
\end{tabular}




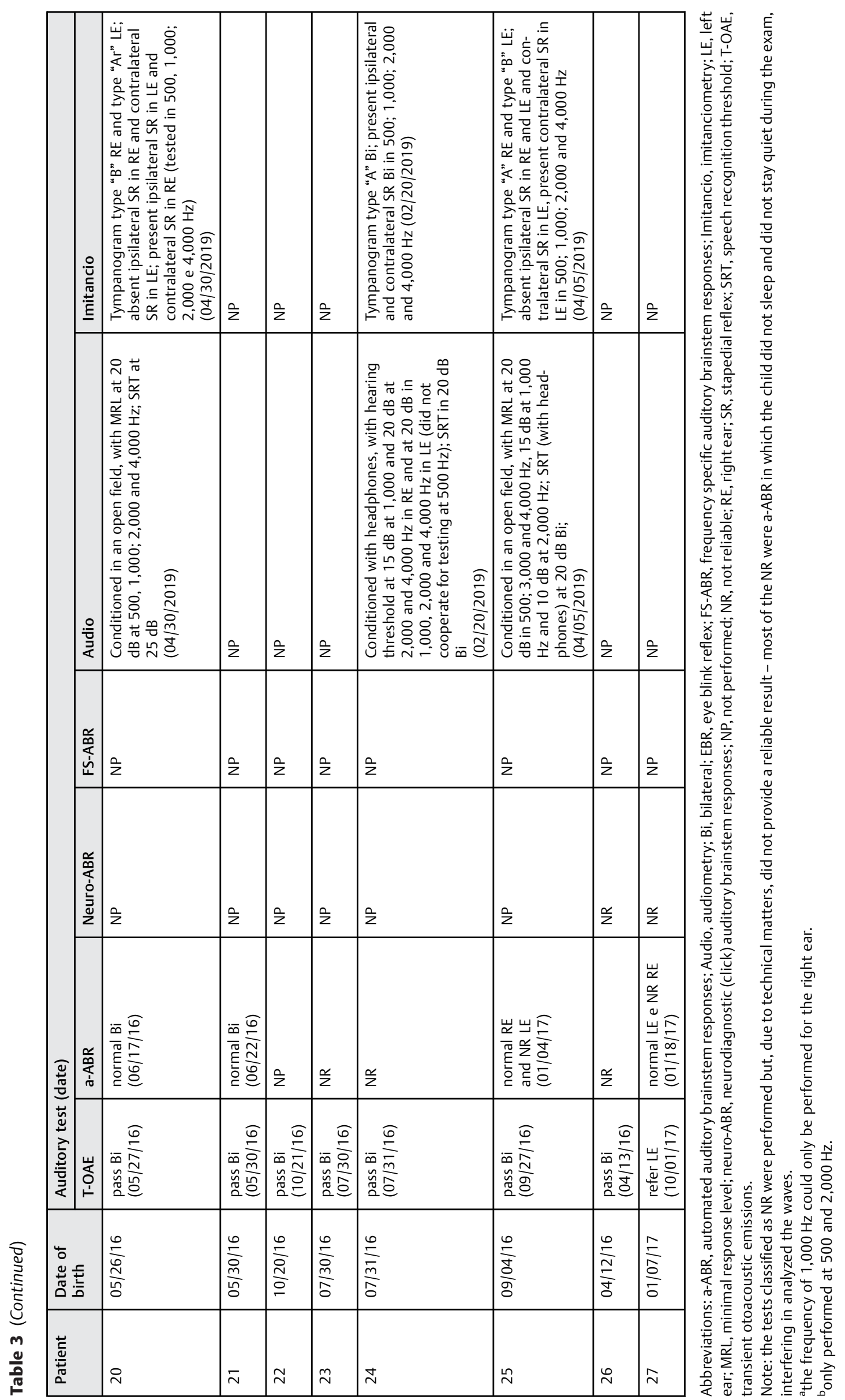


In a review, Leal et al ${ }^{11}$ mentioned a not yet published longitudinal study that assessed children with congenital ZIKV infection up to 18 months of life and seemed to rule out the possibility of a progressive or late onset hearing loss. Nevertheless, the authors recommend auditory follow-up even in children who passed the initial hearing screening. They also emphasize the association between microcephaly and hearing impairment, suggesting a possible central origin in a significant amount of cases, even when presenting normal electrophysiological tests. On the other hand, Marques-Abramov et al $^{30}$ evaluated 19 children with congenital ZIKV infection and microcephaly and found no disturbances in the neural conductibility of the auditory pathways up to the brainstem. However, this finding does not rule out hearing threshold alterations (not tested in the aforementioned study) or a more central auditory path impairment.

In the present study, the only microcephalic child presented normal hearing tests, with positive behavioral audiometry responses at all intensities and frequencies. Motor responses to sound always comprised head lateralization to the left side, suggesting that the child presented preserved hearing function, but that her neuropsychomotor impairment determined this response pattern. Additionally, this does not rule out a possible limitation in certain auditory abilities that depend on the integrity of the auditory cortex, as previously highlighted in other studies. ${ }^{2,11}$

A considerable frequency of maternal comorbidities was present, such as pregnancy-induced hypertension, gestational diabetes, and preexisting chronic diseases. However, most children presented no complications, with only three cases of prematurity and neonatal intensive care unit (NICU) admission and four cases of non-severe and self-limited neonatal jaundice, including two twins, who were among the premature infants admitted to the neonatal intensive care unit (NICU). If any hearing loss were to be identified in those infants, their neonatal complications would have been taken into consideration, as they are known risk indicators for hearing loss. ${ }^{10}$ Therefore, their families were instructed to closely follow neuropsychomotor and linguistic milestones acquisition and to stimulate oral language in the familiar environment. ${ }^{10}$

Some study limitations should be noted, as follows. Confirmation of fetal infection by the ZIKV was not possible. All mothers underwent laboratorial confirmation of the infection during pregnancy, either by a positive RT-PCR or a positive IgM serology. However, confirmation was more complex in the fetuses and newborns, since the risk associated to amniocentesis precluded this procedure as a routine for collecting organic fetus material. As most of the mothers presented the infection in the first two trimesters of pregnancy, newborn IgM serology was expected to be negative, since too much time until birth would have passed. On the other hand, as IgG crosses the transplacental barrier, it could persist in the infant's blood during the first months of life, ${ }^{31,32}$ even in non-infected individuals. The RT-PCR testing in newborns would only be useful if the birth occurred up to two weeks after the infection (window period), which was not the case in the present cohort. The IgG serology after the first year of life may strongly suggest congenital ZIKV infection, but postnatal infection cannot be ruled out, considering the epidemiological characteristics and the presence of the vector and the circulating virus in the region. In this scenario, as the hearing tests were normal, two situations may be considered: 1) the children did not contract intrauterine infection by ZIKV from their mothers. This has been reported for other viral infections, such as rubella, in which the frequency of transmission to the fetus diminishes according to the increased gestational age ${ }^{33} ; 2$ ) the children were infected by ZIKV, but the infection did not determine hearing loss to date. It is worth noting that a considerable portion of studies describing hearing loss in congenital ZIKV infection performed the tests only in microcephalic children, considered the worst clinical manifestation of CZS. ${ }^{1,2,11,27,28}$ On the other hand, the children in this cohort-comprising only one microcephalic individual-could represent a mild spectrum of manifestations, which do not include hearing loss. Another study limitation consists in the reduced number of children submitted to a complete auditory evaluation. In some cases, the caregivers faced difficulties to attend follow-up exams, despite the efforts of the research team to avoid this situation. In other cases, adequate sedation for the FS-ABR test was not possible. Nevertheless, $74 \%$ of the children performed the FS-ABR or audiometry + imitanciometry, the most accurate tests for diagnosing hearing loss in infants, while $63 \%$ performed the combined tests (OAE + any type of ABR + audiometry + imitanciometry), ensuring high sensitivity and specificity. Finally, the ZIKV epidemic progressively waned during the study period, which contributed to the limited number of study participants.

\section{Conclusions}

The results of this study indicate that intrauterine exposure to the ZIKV does not always determine hearing impairment. This risk seems to be more associated to the level of the central nervous system involvement, as demonstrated in other studies. Some cases of middle ear pathology were detected, which are common during the assessed age. The longitudinal and prospective assessments, observed in only a few studies, indicate no late or progressive hearing impairment. However, based on the knowledge of other congenital infections, the maintenance of auditory follow-up in children at risk for hearing loss is advised.

Conflict of Interests

The authors declare that have no conflict of interests.

\section{References}

1 Leal Mde C, Muniz LF. Caldas Neto S da S, van der Linden V, Ramos RCF. Sensorineural hearing loss in a case of congenital Zika virus. Rev Bras Otorrinolaringol (Engl Ed) 2016(xx):1-3 Available at http://www.ncbi.nlm.nih.gov/pubmed/27444419. Accessed Apr 17, 2018 [Internet]

2 Leal MC, Muniz LF, Ferreira TSA, et al. Hearing loss in infants with microcephaly and evidence of congenital Zika virus infection Brazil, November 2015-May 2016. MMWR Morb Mortal Wkly Rep 2016;65(34):917-919 
3 Cohen BE, Durstenfeld A, Roehm PC. Viral causes of hearing loss: a review for hearing health professionals. Trends Hear 2014;18:1-17

4 Chau J, Atashband S, Chang E, Westerberg BD, Kozak FK. A systematic review of pediatric sensorineural hearing loss in congenital syphilis. Int J Pediatr Otorhinolaryngol 2009;73(06):787-792

5 Brown ED, Chau JK, Atashband S, Westerberg BD, Kozak FK. A systematic review of neonatal toxoplasmosis exposure and sensorineural hearing loss. Int J Pediatr Otorhinolaryngol 2009;73 (05):707-711

6 Nogueira ML, Nery Júnior NRR, Estofolete CF, et al. Adverse birth outcomes associated with Zika virus exposure during pregnancy in São José do Rio Preto, Brazil. Clin Microbiol Infect 2018;24(06): 646-652

7 Barbosa MHM, Magalhães-Barbosa MC, Robaina JR, Prata-Barbosa A, Lima MAMT, Cunha AJLA. Auditory findings associated with Zika virus infection: an integrative review. Braz J Otorhinolaryngol [Internet]. 2019;S1808-8694(19). Available at: https://linkinghub.elsevier.com/retrieve/pii/S1808869419300540. Accessed Jun 1, 2019.

8 Ventura CV, Maia M, Dias N, Ventura LO, Belfort R Jr. Zika: neurological and ocular findings in infant without microcephaly. Lancet 2016;387(10037):2502

9 American Academy of Pediatrics, Joint Committee on Infant Hearing. Year 2007 position statement: Principles and guidelines for early hearing detection and intervention programs. Pediatrics 2007;120(04):898-921

10 Harlor ADB Jr, Bower C; Committee on Practice and Ambulatory Medicine; Section on Otolaryngology-Head and Neck Surgery. Hearing assessment in infants and children: recommendations beyond neonatal screening. Pediatrics 2009;124(04):1252-1263

11 de Carvalho Leal M, Ramos DS, Caldas Neto SS. Hearing Loss From Congenital Zika Virus Infection. Top Magn Reson Imaging 2019;28 (01):19-22

12 Adebanjo T, Godfred-Cato S, Viens L, et al; Contributors. Update: interim guidance for the diagnosis, evaluation, and management of infants with possible congenital Zika virus infection - United States, October 2017. MMWR Morb Mortal Wkly Rep 2017;66 (41):1089-1099

13 Borja A, de Araújo RPC. Hearing screening in children exposed to zika virus during pregnancy. Rev Ciênc Méd Biol 2017;16(03):271

14 Fandiño-Cárdenas M, Molina-Franky J, Velandia R, et al. Zika virus infection during pregnancy and sensorineural hearing loss among children at 3 and 24 months post-partum.J Trop Pediatr 2018; $\cdots: 1-8$

15 Heidari S, Manesh AO, Rajabi F. The Sensitivity and Specificity of Automated Auditory Brainstem Response and Otoacoustic Emission in Neonatal Hearing Screening: a Systematic Review. Audit Vestib Res 2015;24(03):32-42

16 Farinetti A, Raji A, Wu H, Wanna B, Vincent C. International consensus (ICON) on audiological assessment of hearing loss in children. Eur Ann Otorhinolaryngol Head Neck Dis 2018;135(1S):S41-S48

17 Stapells DR. Threshold Estimation by the Tone-Evoked Auditory Brainstem Response: A Literature Meta-Analysis. J Speech Lang Pathol Audiol 2000;24(02):74-83
18 Shetty HN, Kooknoor V, Rajalakshmi G. Sensitivity and Specificity of Combined Physiological Tests in Newborn Hearing Screening. J Phonetics Audiol 2016;2(02):

19 Ministério da Saúde. Diretrizes de Atenção da Triagem Auditiva Neonatal [Internet]. Ministério da Saúde 2012 p. 32. Available at: http://bvsms.saude.gov.br/bvs/publicacoes/diretrizes_atencao_triagem_auditiva_neonatal.pdf. Accessed May 22, 2018.

20 British Columbia Children's Hospital, Provincial Health Service Authority. BC Early Hearing Program [Internet]. BC Early Hearing Program. 2012. p. 118. Available at: http://www.phsa.ca/Documents/bcehpaudiologyassessmentprotocol.pdf. Accessed Aug 03, 2019.

21 Otodynamics. Otoport Lite DP [Internet]. Available at: https://www. otodynamics.info/product/otoport-lite-dp/. Accessed Jul 28, 2019.

22 IHS. Intelligent Hearing Systems [Internet]. Available at: http:// www.ihsys.com/site/SmartEP.asp?tab=1. Accessed Jul 28, 2019.

23 Interacoustics. Interacoustics [Internet]. Available at: https:// www.interacoustics.com. Accessed Jul 28, 2019.

24 World Health Organization. Pregnancy management in the context ofZika virus Interim guidance 2 March 2016 [Internet]. 2016 p. 1-14. Available at: http://apps.who.int/iris/bitstream/10665/204520/1/ WHO_ZIKV_MOC_16.2_eng.pdf?ua=1. Accessed Aug 3, 2019.

25 Klase ZA, Khakhina S, Schneider AdeB, Callahan MV, GlasspoolMalone J, Malone R. Zika Fetal Neuropathogenesis: Etiology of a Viral Syndrome. PLoS Negl Trop Dis 2016;10(08):e0004877

26 Microcephaly Epidemic Research Group. Microcephaly in Infants, Pernambuco State, Brazil, 2015. Emerg Infect Dis 2016;22(06): 1090-1093

27 Satterfield-Nash A, Kotzky K, Allen J, et al. Health and Development at Age 19-24 Months of 19 Children Who Were Born with Microcephaly and Laboratory Evidence of Congenital Zika Virus Infection During the 2015 Zika Virus Outbreak - Brazil, 2017. MMWR Morb Mortal Wkly Rep 2017;66(49):1347-1351

28 Silva Mde A. Mendonça de Araújo FC. Hearing screening in children exposed to Zika virus. In: II Congresso Brasileiro de Ciências da Saúde. Campina Grande - Paraíba; 2018

29 Leite RFP, Santos MSA, Ribeiro EM, et al. Hearing Screening in children with Congenital Zika Virus Syndrome in Fortaleza, Ceará, Brazil, 2016. Epidemiol Serv Saude 2018;27(04):e2017553

30 Marques Abramov D, Saad T, Gomes-Junior S-C, et al. Auditory brainstem function in microcephaly related to Zika virus infection. Neurology 2018;90(07):e606-e614

31 Chen J, Hu L, Wu M, Zhong T, Zhou YH, Hu Y. Kinetics of IgG antibody to cytomegalovirus (CMV) after birth and seroprevalence of anti-CMV IgG in Chinese children. Virol J 2012;9(01):304

32 Palmeira P, Quinello C, Silveira-Lessa AL, Zago CA, CarneiroSampaio M. IgG placental transfer in healthy and pathological pregnancies. Clin Dev Immunol. [Internet] 2012; Published online 2011 Oct 1. Available at: https://www.ncbi.nlm.nih.gov/pmc/articles/PMC3251916/. Accessed Apr 142019.

33 De Santis M, Cavaliere AF, Straface G, Caruso A. Rubella infection in pregnancy. Reprod Toxicol 2006;21(04):390-398 